\title{
“Reaprender a ver o mundo": o cinema como educação do olhar ${ }^{1}$
}

\author{
Avelino Aldo de Lima Neto \\ Terezinha Petrucia da Nóbrega ${ }^{3}$
}

\section{Resumo}

0 presente artigo apresenta o cinema como uma experiência de educação vivenciada a partir do olhar. Para tanto, parte-se da constatação do problemático esquecimento da potência epistêmica da visibilidade nas práticas educativas. Inicialmente, retoma-se o momento platônico de fixação do paradigma gramatical e a sua associação à uma determinada postura corporal - estar sentado -, com a consequente exclusão da visão e do movimento. Tal postura é retomada com o cinema, fundador de uma inteligência que não despreza, mas suplanta a enunciação linguística, uma vez que se enreda nas dinâmicas da visibilidade, possíveis graças à articulação entre as duas supracitadas categorias excluídas por Platão. Esta abordagem é desenvolvida a partir do aporte teórico com um texto fundamental da filosofia francesa contemporânea: $O$ olho e $o$ espirito, de Merleau-Ponty, que reabilita epistêmica e ontologicamente o corpo - e, por conseguinte, a visão e o movimento. Esta exploração se efetiva na descrição de algumas cenas do filme Vermelho como o céu, nas quais o espectador é convocado a desdobrar-se numa performance visual, solicitando-lhe imergir numa tensão entre as intenções do cineasta e as exigências das próprias imagens. Conclui-se indicando elementos oriundos da referida performance, que apontam elementos para uma reconfiguração educativo-epistêmica a partir do olhar. Através dele, o protocolo da percepção e o registro do inteligível são atordoados. 0 cinema como educação do olhar faculta-nos modos outros de dizer, de ver, de pensar a realidade educativa, exigindo, doravante, uma epistemologia que dê conta das exigências das imagens.

\section{Palavras-chave}

Cinema - Educação - Olhar - Visibilidade - Imagem.

1- 0 presente artigo é parte de uma tese de doutorado em Educação, realizada em regime de cotutela entre a Universidade Federal do Rio Grande do Norte e a Université Paul Valéry - Montpellier III, sob a orientação de Terezinha Petrucia da Nóbrega e Jacques Gleyse.

2- Instituto Federal de Educação, Ciência e Tecnologia do Rio Grande do Norte, Natal, RN, Brasil.

Contato: avelino.lima@ifrn.edu.br

3- Universidade Federal do Rio Grande do Norte, Natal, RN, Brasil.

Contato: pnobrega68@gmail.com

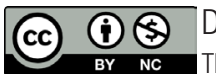

DOl: http://dx.doi.org/10.1590/S1678-463420180144162138

This content is licensed under a Creative Commons attribution-type BY-NC. 


\section{"Re-learn how to see the world": cinema as education of the way of looking}

\section{Abstract}

The present article presents the cinema as an experience of education based on the way of looking. For such, it starts with the problematic oblivion of the epistemic power of visibility in educational practices. Initially, the platonic moment of fixation of the grammatical paradigm is resumed with its association to a given body posture - being seated -, which consequently excludes vision and movement. This position is regained with the cinema, founder of an intelligence that does not despise but supersedes the linguistic enunciation, since it is enmeshed in the dynamics of visibility, made possible by the articulation between the two above mentioned categories excluded by Plato. This approach is developed in the perspective of the theoretical contribution from a key text of contemporary French philosophy, The Eye and the Spirit, by Merleau-Ponty, who epistemically and ontologically rehabilitates the body, and consequently the vision and movement. This exploration is carried out in describing some scenes from the film Red as the sky, in which the viewer is called to unfold a visual performance and is asked to dive into a tension between the intentions of the filmmaker and the demands of the very images. I conclude by indicating elements from this performance, which point out elements for an educative-epistemic reconfiguration based on the way of looking. Through it, the protocol of perception and the level of intelligibility are stunned. Cinema as education of the way of looking grants us other ways of saying, of seeing, of thinking about the educational reality, and requires henceforth an epistemology able to cope with what is demanded by the images.

\section{Keywords}

Cinema - Education - Way of looking - Visibility - Image.

\section{Introdução: Teeteto está sentado}

As cenas que ora evocamos estão em dois diálogos platônicos, e ligam-se à instituição de maneiras de dizer e de pensar. Sem nenhuma intenção de fazer a exegese dos textos, resumimo-nos a associar tais cenas à nossa afasia diante das múltiplas problemáticas que povoam o fenômeno educativo. Parece-nos que os discursos, embora excessivos e, não raro, repetitivos, não conseguem mais dar conta da complexidade do supracitado fenômeno. Nesse contexto, somamo-nos àqueles que buscam outros modos de abordá-la ${ }^{4}$, e fazemo-lo

4- Referimo-nos aos trabalhos de Duarte (2006), Fischer (2013), Fresquet (2013), Nóbrega (2015; 2016) e de muitos outros pesquisadores brasileiros e estrangeiros que, de modo inter e transdisciplinar, abordam a educação pelo viés da imagem. 
por um viés estético, ao buscar no cinema uma inteligência capaz de desencadear, por uma educação do olhar, novas e distintas formas de ver - e não só de dizer - a educação.

Abordaremos esta problemática obliquamente: a partir de uma filosofia do corpo e da imagem que, na modernidade - compreendida não como periodização, mas como qualificação das nossas negociações entre o real e o inteligível - desvelou outros modos de efetuar esses dois registros. Fazemo-lo evocando Merleau-Ponty (2004), por compreender que, na filosofia francesa contemporânea, ele foi pioneiro ao constatar o esgotamento de uma cultura logorreica ${ }^{5}$, indicando concomitantemente o nascimento de uma cultura visual. Suas obras, assim, também se constituem em esforços para uma recuperação do olhar como experiência de conhecimento.

Inicialmente, vamos à introdução do diálogo Teeteto (PLATON, 1923, 143d-151d). Platão aí descreve o encontro entre Sócrates e o jovem que dá nome ao diálogo, encontro este possibilitado por Teodoro, geômetra e professor de Teeteto:

[144d] Sócrates - Falas de um homem nobre. Chama-o, então, para se sentar aqui. Teodoro Vou fazê-lo. Teeteto, vem aqui para perto de Sócrates! Sócrates - Isso mesmo, Teeteto. Assim eu poderei observar-me a mim mesmo e ver de que tipo é o meu rosto; [144e] pois Teodoro diz que se parece com o teu. ${ }^{6}$ (grifos nossos).

Agora, Teeteto não andará mais, ele se sentará próximo a Sócrates. 0 aqui do texto não dá nenhuma especificação de lugar. Cessa-se um determinado movimento. Outro, a partir do olhar de Sócrates sobre o seu rosto, começará. Platão estabelece um ponto de partida, uma posição fixa a partir da qual introduzimos a observação do mundo: estar sentado.

Já em $O$ sofista, Teeteto dialoga com um estrangeiro vindo de Eleia. 0 estrangeiro diz: "Teeteto está sentado" e, logo após, “Teeteto, com quem presentemente eu dialogo [...]” (PLATON, 1955, 263a 2; 263a 9, grifos nossos). Aqui o diálogo continuará com o interlocutor assumindo a tarefa de enunciar a realidade a partir da física. Ser, repouso e movimento serão gramaticalizados, formando um verdadeiro programa de estudos que incluirá uma física, uma maneira de dizer e de conjugar (IMBERT, 1999, p. 07). Ademais, o estrangeiro aborda esse presente, no qual aprendemos, em seu duplo: ele põe "em coincidência a instância do diálogo e suas coordenadas do mundo, isto é, os estados de repouso e de movimento que a sustentam e que a atravessam" (IMBERT, 1999, p. 17).

Estamos diante das primeiras cenas que poderíamos dizer "escolares" na história da filosofia. Não só porque Teeteto e $O$ sofista fazem parte dos ditos diálogos escolares de Platão, mas porque entre o "estar sentado" e o "com quem presentemente eu dialogo" está em jogo a conquista de uma nova postura - uma posição fixa - de observação do mundo. Ambos, sentados, parados, isolados do resto da cidade, ocupam um novo espaço,

5- Por cultura logorreica entendemos a centralização exacerbada na palavra como meio, na cultura ocidental - especialmente na filosofia, nas ciências humanas e sociais - de se aproximar e de explicar o real, em detrimento da imagem (muito embora esta esteja presente desde 0 início dos primeiros registros dos seres humanos, com a arte rupestre, por exemplo). 0 que problematizamos, por outro lado, não é um falar sobre as imagens - o que estes campos e outros campos do conhecimento já fizeram - mas um pensar segundo a imagem, como lembra Alloa (2015) a propósito do trabalho de Merleau-Ponty em 0 Olho e o Espirito.

6- Traduzimos livremente esse excerto a partir das traduções oficiais em língua francesa e em língua portuguesa, a fim de torná-lo mais compreensivel para um leitor brasileiro (Cf. PLATON, 1923, p. 159-160; PLATÃ0, 2010, p. 191). 
um novo cenário. Este, "mais que um fragmento de tempo e espaço", era "um lugar ainda não inscrito no cadastro da cidade, uma acrópole mental” (IMBERT, 1999, p. 08). Aquilo que, voluntariamente anacrônicos, chamaríamos de heterotopia - tomando emprestado o termo cunhado séculos depois por Michel Foucault (2001, 2009).

0 enunciado fundamental de uma outra educação aí se deu, enunciado ao qual correspondeu uma posição educativa por nós bem conhecida: estar sentado. Teeteto está sentado: afırmação que resume o "paradigma gramatical" (IMBERT, 1999, p. 19) apresentado em $O$ sofista, ela é, ao mesmo tempo, um lugar a partir do qual se pôde traçar a participação do sensível e do inteligível no mundo. Isso implicou, evidentemente, uma certa escolha, a qual traz consigo uma inevitável privação, dado que quando estabelecemos um problema, devemos às vezes suprimir uma variável. Para falar do mundo por meios físicos, foi preciso sacrificar a visão. Nós, no cinema, ao invés, recuperamo-la - malgrado permaneçamos, como Teeteto, sentados. Nesse caso, porém, o fazemos para reaprender a dizer o real, ou melhor, para "reaprender a ver o mundo" (MERLEAU-PONTY, 2011a, p. 19). Agora, um regime discursivo deverá associar-se a uma outra economia do visível.

\section{No cinema com Merleau-Ponty}

Depois dessa cena inicial, pomo-nos na mesma posição de Teeteto: sentados, em face de algumas cenas do filme Vermelho como o céu (Rosso come il cielo, 2006), drama italiano dirigido por Cristiano Bortone. 0 filme, de narração objetiva, desenvolve-se nos campos da Toscana, no verão de 1970, inspirado na história verídica de Mirco Balleri. Depois de um acidente, o menino, de apenas 10 anos, fica cego. Para continuar seus estudos, é obrigado a ingressar no Instituto Cassoni, escola voltada especialmente para meninos deficientes visuais. Sua relação com a cegueira começa a se modificar quando encontra um gravador. A partir de então, começa a fazer novas experiências táteis e sonoras, que modificarão sua relação com o próprio corpo e subjetividade, com a educação, com a natureza, com os outros, com o mundo.

No cenário, temos a escola - sombria, com arquitetura claustral - as ruas de Gênova, a fornalha e o cinema. 0 som desempenha, neste filme, papel central, haja vista ser por meio dele que Mirco reconfigura seu corpo. As cores e tons variam à medida que a situação do menino muda. É como se os tons e cores acompanhassem a situação visual dele. A frequência de enquadramento em primeiríssimo plano nos faz quase sentir os olhos, as mãos e os pés de Mirco. Aqui, várias cenas nos apresentam o esquema corporal readaptando-se aos novos espaços, ao mesmo tempo em que recria os sentidos da educação.

Assim, o enredo, a montagem e as outras estratégias técnicas postas em marcha pelo cineasta justificam a nossa escolha por esta película, pois a sua articulação privilegiada entre o olhar, a visibilidade fílmica e a experiência educativa doa-nos elementos significativos para apresentar o cinema como educação do olhar. Como faz o pintor ao qual MerleauPonty alude em $O$ olho e o espirito, deixamos que tais cenas se mostrassem para nós e que nós a interrogássemos com o olhar (MERLEAU-PONTY, 2004, p. 21). Interrogar a educação enquanto cena significa, em primeiro lugar, a imersão, no universo do visível, de nosso esforço de compreensão. Em segundo lugar e, por consequência, assumimos um 
papel semelhante ao do pintor em $O$ olho e o espírito: pedimos ao fenômeno educativo que ele nos revele os meios visíveis através dos quais ele se constitui, enquanto tal, aos nossos olhos. Em nosso caso, dirigimo-nos à sétima arte como meio para ver o visível (MERLEAU-PONTY, 2004, p. 21).

Isso se dá de dois modos. Inicialmente, no âmbito de como o fenômeno da educação é filmado. Aqui, interessamo-nos sobre como o corpo se mostra. Em segundo lugar, perguntamo-nos como as pessoas o veem no cinema, o que, por sua vez, indica-nos pistas sobre como podemos vê-lo. Tal percurso não se efetiva, todavia, num contexto de dissimetria e evergetismo ${ }^{7}$, como se esperássemos da visão um presente divino. Não fazemos "a pergunta daquele que sabe àquele que ignora, pergunta do mestre-escola", lembra o filósofo, mas a própria pergunta se faz em nós pela visão (MERLEAU-PONTY, 2004, p. 21), e isso o cinema nos permite. A efetivação desta pergunta foi possibilitada ao inspirarmo-nos na fenomenologia de Merleau-Ponty para a organização metodológica deste trabalho - o que nos exige "incorporar a atitude ancorada na experiência vivida [...] com o intuito de compreendê-la" (NÓBREGA, 2010, p. 38).

No texto $O$ cinema e a nova psicologia encontramos cinco pistas deste exercício fenomenológico, as quais passamos agora a explicitar brevemente ${ }^{8}$. Primeiramente, é preciso ver o conjunto. Não se trata de juntar peças de uma quebra-cabeça, mas de deixar que a integridade da cena se organize diante do olhar. Em segundo lugar, assumimos que os sentidos percebem conjuntamente, o que quer dizer que o campo visual é também corporal, uma vez que solicita todos os sentidos do corpo para dar-se à percepção. Em terceiro lugar, é necessário olhar com o corpo. 0 ódio, o amor, a raiva, e outros sentimentos, numa cena fílmica, podem ser lidos nos gestos, pois é pela própria natureza do corpo que o fenômeno da expressão se dá. Em quarto lugar, reconhecemos a importância dos ritmos e tempos, afinal, "o filme não é uma soma de imagens, mas uma forma temporal" (MERLEAU-PONTY, 1996b, p. 69), o que demanda uma atenção especial à montagem enquanto síntese do tempo e da imagem, organizando o sentido. Por fim, faz-se mister estar atento aos diálogos, às músicas e ao silêncio, uma vez que eles tornam sensível o ritmo interno da imagem, podendo, portanto, transformá-la.

Em resumo, levamos em consideração o campo visual e não o aparelho óptico; o emprego dos vários sentidos e as suas implicações; o envolvimento da postura e do gesto na visão; o ritmo fílmico - que desempenha no contexto da montagem uma função paralela à do tempo de uma aula ou de outras estratégias de ensino; o envolvimento dos sons nas estratégias de formação e informação ligadas a um regime sensorial. Esses são os cinco critérios oriundos de $O$ cinema e a nova psicologia, e é por meio deles que estabelecemos uma ligação entre o olhar, a visibilidade fílmica e a experiência educativa. Amálgama de visão e movimento, o cinema oferece esboços para uma outra partilha do

\footnotetext{
7- Por evergetismo entendemos, de modo geral, as práticas de doação-recepção, sem participação ativa daquele que recebe. Tal prática nasce com o costume que certos proprietários, nas culturas helenística e romana, tinham de ofertar "presentes" à população ou ao espaço público. Em nossas sociedades, a doação-recepção se expande para outros domínios da vida cotidiana, como as relações educativas e aquelas que mantemos com os artefatos artísticos. Para um maior aprofundamento no conceito, cf. Veyne, 1976. p. 15-29.

8- Em outra ocasião, exploramos mais demoradamente os aspectos metodológicos oriundos deste texto de Merleau-Ponty. cf. Lima Neto; Nóbrega, 2015.
} 
visível na experiência educativa. Cartografaremos outros modos de nela nos situarmos e de nos movimentarmos - movimento que, por si, implica outros modos de ver, posto que "o mundo visível e de meus projetos motores são partes totais do mesmo Ser" (MERLEAUPONTY, 2004, p. 16). Esse processo nos revelará as implicações do cinema como educação do olhar, implicações estas diretamente relacionadas ao encadeamento de experiências nascidas da imersão visual do corpo vidente-visível.

Em Merleau-Ponty, a imagem se doa como possibilidade outra de configuração de uma experiência de subjetivação. Mas por reconfigurar as possibilidades desta experiência, é também um outro modo de conhecimento que está em questão - haja vista que não há experiência de conhecimento sem o sujeito. Ontologia e epistemologia se cruzam, portanto, na imagem. Tal empiètement ${ }^{9}$ faculta-nos uma leitura da atualidade a partir do enigma da carne, este "tipo de desvelamento do mundo, sem pensamento separado" que “é, precisamente, ontologia moderna” (MERLEAU-PONTY, 1996c, p. 206).

0 que propomos aqui não é, todavia, uma reflexão sobre a ontologia, sobre o Ser - empreitada cuja relevância parece-nos evidente e que já vem sendo realizada pelos estudiosos de sua obra, tais como Barbaras (2001, 2013) e Bimbenet (2004). Dedicamonos, ao invés, a pensar os modos de ser, que numa terminologia cunhada pelo talvez mais célebre ex-aluno de Merleau-Ponty - Michel Foucault -, diríamos modos de subjetivação. O olho e o espirito nos permite fazê-lo. Trata-se de um manuscrito de caráter positivamente ambíguo: é testamentário, pois é o último que o autor termina em vida; e, justamente, para fazer jus a esta característica, o referido texto é um canteiro de trabalho, uma vez que a filosofia merleau-pontiana - como o fenômeno da corporeidade sobre o qual ela se debruça - é uma filosofia do inacabamento. Neste testamento-canteiro, pelo recurso à pintura - e, num sentido mais amplo, à imagem - o filósofo retorce a tradicional noção de experiência, noção que a empresa crítica kantiana aprisionou no esquematismo transcendental. Disponibilizam-se, então, as linhas de um outro registro do inteligível, calcado na imagem.

Ora, vale ressaltar que, anos antes, no editorial A guerra aconteceu (MERLEAUPONTY, 1996a), Merleau-Ponty foi pioneiro ao diagnosticar a nossa incapacidade de formular a experiência da catástrofe da Segunda Grande Guerra, dada a afasia e a cegueira das quais fomos acometidos. Lamenta essa cegueira que nos impediu não de captar um certo sentido da história, como se ela se movesse para um certo telos - posição sartreana -, mas a incapacidade de "ver e entender o que acontecia efetivamente" (REVEL, 2015, p. 138). Todos estavam misturados, envolvidos naquela realidade: um empiètement que perturbou os protocolos da percepção. Não podiam nem vê-la bem, nem dizê-la bem. 0 corpo da guerra deixou-nos - a nós e a filosofia - cegos e afásicos.

A conclusão da Fenomenologia da percepção já apontava para esta disjunção patológica entre a teoria e o envolvimento da liberdade no mundo (MERLEAU-PONTY, 2011a, p. 612). Por outro lado, paradoxalmente, tais obscuras deficiências foram postas às claras pela primeira vez na sala escura: no cinema, com o documentário Noite e

9- Optamos por não traduzir a palavra francesa empiètement, dado seu lugar central na construção do pensamento de Merleau-Ponty. Em língua portuguesa, tal termo tem valor semântico próximo a invasão, imbricamento, transgressão. 
neblina (1955), de Alain Resnais, em seu estilo de testemunha ocular. Um outro registro do inteligível se esboçava, assim, simultaneamente, na filosofia e no cinema. MerleauPonty, em $O$ olho e o espírito, produz não um documentário, mas lentes para ver o visível e indicações para nele nos mover.

Não desprezamos que, nesse contexto, a noção de carne em Merleau-Ponty é um operador teórico medular. A carne do mundo aparece como uma formação lexical que foge ao uso predicativo reinante no universo filosófico. Trata-se de uma verdadeira “montagem em filosofia", pois não são nem conceito nem categoria - no sentido com o qual nos acostumamos e nos imobilizamos a partir do criticismo kantiano. A carne mesma é montagem, em fórmula linguística, das operações do corpo no mundo (IMBERT, 2016) - tal como a montagem, no cinema, exerce, dentre outras, uma função de reorganização da percepção.

Em $O$ olho e o espirito, em íntima associação com o olhar e com o movimento, a carne é figura de contraposição à racionalidade científica de sobrevoo, e indica outra experiência de inteligibilidade do real, fundada no visível. Ela contrapõe-se ao pensamento enquanto articulação de técnicas para a captação da realidade, ou como instrumento de organização de uma lógica implícita. Ele quer, na verdade, reencontrar, por meio da interrogação do olhar e da pintura, a ciência secreta do pintor.

Entretanto, concordamos com Saint Aubert (2013) sobre o fato de não podermos entender este ensaio desvinculado de todo o esforço que Merleau-Ponty empreendeu, desde a Fenomenologia da percepção, na construção de sua filosofia. Do contrário, correríamos o risco de inserir o filósofo num mero esteticismo, quando, na verdade, o seu trabalho acerca da expressão, embora originário da linguística e da estética, é "matriz de seu pensamento da história e da esfera política” (REVEL, 2015, p. 123). 0 texto acima aludido participa do desenvolvimento de seu projeto ontológico, "nutrido de uma antropologia que determina a vida perceptiva e motora" (SAINT AUBERT, 2013, p. 24) e que se estende ao mundo político.

Por isso, quando nele o filósofo afirma que a pintura ilustra o enigma do corpo, num sistema de trocas, é a um longo processo de amadurecimento do lugar do corpo no conhecimento, mediado pelo conceito do esquema corporal, que ele alude. A reorganização da experiência sensivel proposta por Merleau-Ponty, que em seus escritos sobre a pintura encontrará na imagem um operador essencial, exige-nos essa consciência.

Para o filósofo, “a imagem é mal afamada porque se julgou irrefletidamente que o desenho fosse apenas um decalque, uma cópia” (MERLEAU-PONTY, 2004, p. 18) que representa algo ausente. Na verdade, ela é um modo de relação com a realidade, com a atualidade, haja vista que entre ela e o meu corpo existe uma reversibilidade do sentir. Não se trata de uma abstração cujo objetivo é acessar uma lógica representativa, na qual o objeto me é dado à mente. A reversibilidade se constitui numa "potência analógica do esquema corporal, que inverte os espaços corpóreos (notadamente o dentro e o fora) e os pontos de vista (as perspectivas vividas, as situações) no esquematismo sensório-motor e no imaginário, estimulando a ação" (SAINT AUBERT, 2013, p. 266-267).

É por isso que nas notas do curso A ontologia cartesiana e a ontologia hoje (19601961), o filósofo se referirá a uma certa "carne do imaginário", capaz de fazer-nos 
compreender "como a visão emerge de nosso corpo" por meio do empiètement entre a visão e o movimento, numa reversibilidade própria do esquema corporal (MERLEAUPONTY, 1996c, p. 173). Ser carne é condição inerente à existência corporal, é ser videntevisível. A pintura, ao interrogar a "gênese secreta e febril das coisas em nosso corpo" (MERLEAU-PONTY, 2004, p. 21), visa essa outra experiência do corpo com o mundo e com os outros. Uma experiência que despreza a ordem linear dos signos e de seus significados, de uma lógica de apreensão do objeto pelo sujeito.

0 regime do visível instalado pela pintura "confunde todas as nossas categorias ao desdobrar seu universo onírico de essências carnais, de semelhanças eficazes, de significações mudas” (MERLEAU-PONTY, 2004, p. 23). Ora, tanto a ciência quanto a filosofia, para o filósofo, são heranças de um pensamento cartesiano, que matematiza a visão, o espaço e o corpo num mundo que está diante de mim - como se percebe na Dióptrica. 0 filósofo, ao invés, desde a sua tese, já pensava a relação do homem com o mundo a partir das dinâmicas do hábito e da incorporação, que desmantelam e ultrapassam uma lógica objetiva em relação ao espaço.

0 universo onírico suscitado pelas imagens não se limita, todavia, à pintura. Também no cinema o acessamos ${ }^{10}$. A partir de agora, realizaremos o exercício de imergir neste universo através do recurso ao filme Vermelho como o céu, a fim de compreender a maneira pela qual o filósofo se propôs, desde a introdução da Fenomenologia, a transformar a filosofia numa experiência do olhar.

\section{"Reaprender a ver o mundo"}

Desde sua tese até os últimos escritos, sobretudo 0 visivel e o invisivel, é possível observar um movimento que vai da palavra Palavra ao Ser, encontrando-se o problema da expressão - e, por conseguinte, da corporeidade - como via através da qual MerleauPonty tentou chegar à uma ontologia sensível. Ontologia moderna, frisava ele, uma vez que se vinculava a uma renegociação das relações entre o real e o inteligível, alvo que o filósofo perseguiu, sabemo-lo, pelo corpo.

Assim, presentemente, acompanharemos o filósofo num movimento que vai, lentamente, das palavras ao olhar, do dizivel ao visível, cruzando as imagens do filme e seus escritos. E, aí, não podemos esquecer, como lembra Claude Lefort, que Merleau-Ponty "escreve sobre a linguagem, mas é na visão do pintor que ele procura o [seu] segredo" (LEFORT, 1978, p. 141) - como o mostra A linguagem indireta e as vozes do silêncio (2004), outro texto do filósofo que participa da construção de uma outra inteligência, fundada numa linguagem que suplanta a fórmula gramatical. É nesse contexto que se insere a problematização de nossos horizontes educativos, daquilo que podemos ver.

0 personagem Mirco, de Vermelho como o céu, ajudou-nos a problematizar esse papel. Uma inflexão do olhar - do cineasta, do espectador e do personagem -, começará com a cena do acidente sofrido pelo menino: na cozinha de sua casa, ele tem o olhar

10 - E isso o filósofo mostrará em 0 cinema e a nova psicologia, texto publicado, como a Fenomenologia e o supracitado editorial, em 1945. Aí se encontra de modo mais sistematizado, inspirado na Gestalt, uma verdadeira cartografia do ver. Trata-se de indicações sobre os modos pelos quais o olhar é convocado, nas imagens, a uma outra forma de percepção (LIMA NETO; NÓBREGA, 2015). 
atraído para cima: um fuzil que estava fixado na parede. Com a curiosidade própria da criança, põe um pequeno banco sobre uma cadeira, e sobe até alcançá-lo 0 diretor explorará, nas cenas que se seguem, diferentes ângulos, enquadramentos e movimentos da câmera, deslocando o nosso olhar no cenário e no corpo do personagem, como podemos ver na sequência 1.

Com um travelling ${ }^{11}$ da câmera de baixo para cima, acompanhamos a instabilidade daquela "escada" criada por Mirco. Sentimos incerteza, insegurança, mas sobretudo medo do que está por vir. Num plano americano ${ }^{12}$, o cenário está todo desenhado; posteriormente, em plano-detalhe, ângulo normal e perfil, sentimos o desequilíbrio nos pés de Mirco. Segue-se, num primeiro plano, a queda do fuzil, que dispara e espalha cacos de vidro. Estes atingem os olhos Mirco, que cai.

Sequência 1 - 0 espectador no exterior
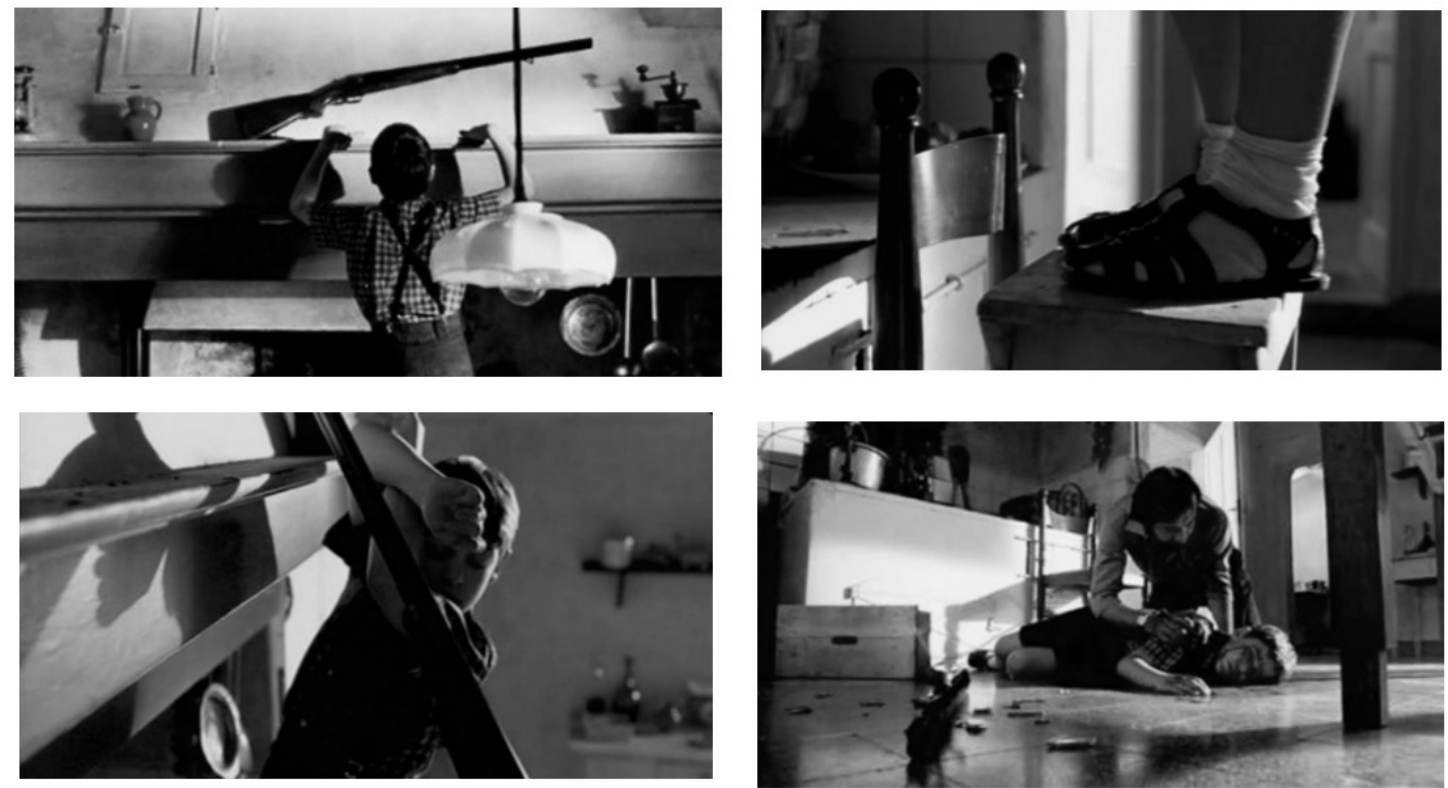

Fonte: DVD de Vermelho como o céu (2006).

Os sentimentos anteriormente evocados confirmam a sua legitimidade. Dos olhos de Mirco, cheios de brilho e curiosidade diante do mundo, escorre o sangue. Sangue que é vermelho como o fogo, e vermelho como o céu por ocasião do pôr do sol - imagens que o próprio personagem evocará algumas cenas à frente.

Depois do acidente, o menino passa a ver somente vultos que, pouco a pouco, tornam-se sombras e, enfım, escuridão total. Sua mudança para o Instituto Cassoni é não somente uma mudança de lar, mas uma mudança de modo de ser. Esta causará em nós,

11- 0 travelling (gerúndio do verbo "viajar", em inglês) é um deslocamento da câmera no espaço.

12- Num plano americano, o personagem é enquadrado do joelho para cima. 
espectadores, uma mudança no modo de ver. Agora ele não se vê mais nos campos da Toscana, nos quais corria e brincava. Mirco depara-se com a limitação de seus movimentos por causa da cegueira e do internamento no Instituto Cassoni.

Com a progressiva perda da visão, será necessário reaprender a mover-se. E aqui não nos referimos somente ao movimento do corpo no espaço físico, mas à retomada da responsabilidade sobre o seu corpo. 0 menino também deverá reformular a maneira de se comunicar, já que não poderá mais dispor da linguagem escrita das pessoas que veem. Deverá aprender o braile. No fundo, Mirco passará por uma reconstrução do seu esquema corporal e da sua operação de significação do mundo.

0 cineasta integra a nós, espectadores, nesse processo. Isso se dá à medida que, ao longo da trama, somos deslocados: os ângulos, planos e enquadramentos - e, com papel destacado, os sons - nos retirarão de uma posição de exterioridade completa para assumir a pele do próprio Mirco. Esse processo começa quando o menino se despede dos pais: num travelling que fecha cada vez mais o ângulo normal, assumimos, pela primeira vez, a pele, a visão de Mirco, até então capaz de ver vultos. 0 ingresso naquela escola significará para Mirco o início de um ritual de iniciação ao mundo dos cegos - e nós, igualmente, seremos aí iniciados. Doravante, nosso olhar não será mais o mesmo.

Sequência 2 - 0 engajamento no corpo do protagonista
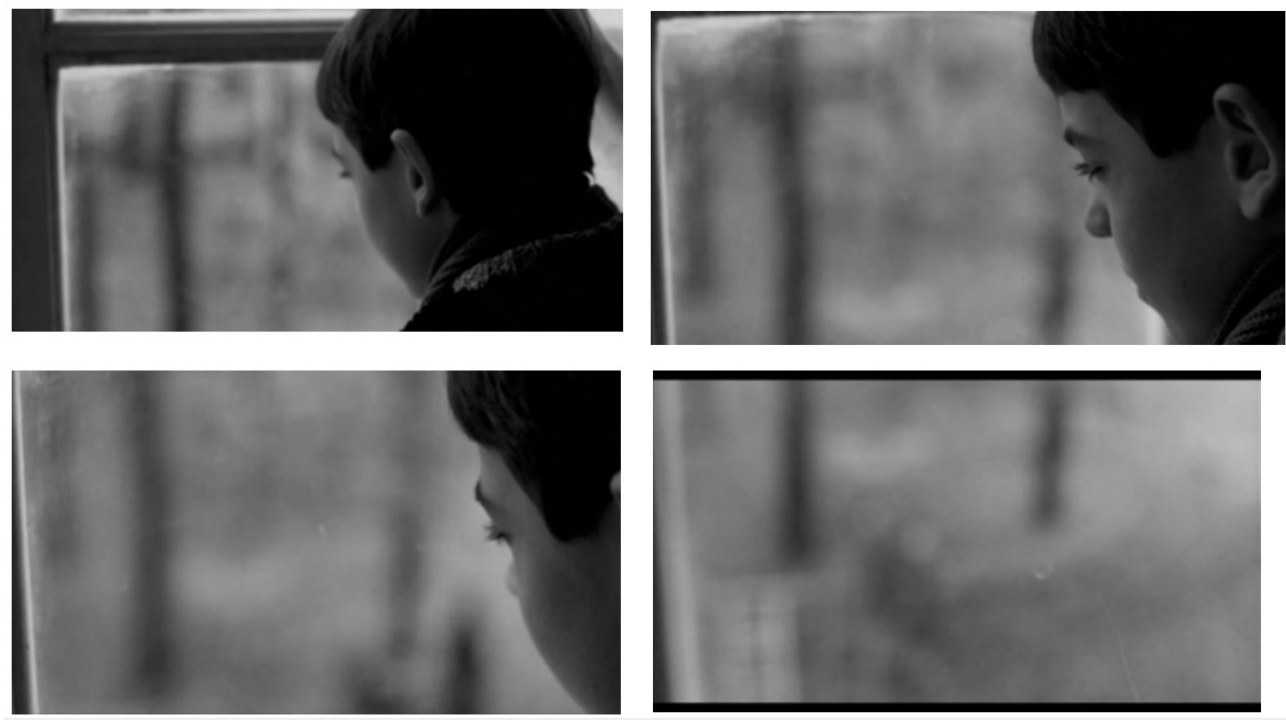

Fonte: DVD de Vermelho como o céu (2006)

Esse engajamento diferenciado do espectador continuará quando o menino anda pela primeira vez no espaço da escola, na cena em que vai ao refeitório. Nela, os ruídos são compostos pelo alto volume dos talheres que as crianças batem nos pratos, bem como pelo som das cadeiras sendo arrastadas e pelas inúmeras vozes, das quais, devido ao aglomerado de sons, não podemos decifrar uma palavra. 
Sentimo-nos como ele que, dando os primeiros passos na cegueira, está confuso e perturbado pelo turbilhão de burburinhos ao seu redor. Mas, aí, há um diferencial: pelo enquadramento, plano e ângulo da câmera, somos engajados no corpo dos personagens. Tornamo-nos um dos meninos cegos que está naquela mesa. As "boas-vindas" que o diretor dá a Mirco são, também, boas-vindas ao espectador que assume, naquele refeitório, um lugar: "Estou seguro de que vocês o acolherão como um de vocês".

Sequência 3 - 0 engajamento do espectador no corpo dos personagens
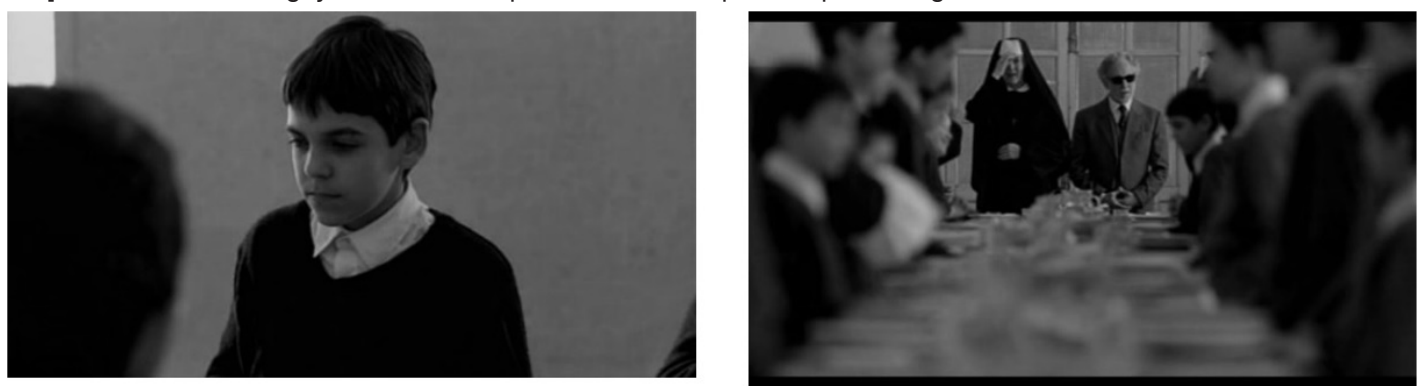

Fonte: DVD de Vermelho como o céu (2006).

Todavia, nesse momento, ao ocupar o lugar de um dos alunos, somos apenas em parte um entre eles. Isto porque, paradoxalmente, assumindo o corpo de um personagem cego, ainda podemos ver. Mais que nos perguntarmos sobre quais seriam as intenções do diretor ao nos encarnar nesse estranho papel - mas também no papel de Mirco - essa atitude nos aproxima dos questionamentos de Merleau-Ponty sobre o regime expressivo, imerso nas relações entre a linguagem e a visibilidade.

De todo modo, pelo som, começamos a nos inserir gradativamente num novo universo sensível. Ora, o que este conjunto de sensações nos diz, ele o faz não porque nos remete imediatamente às ideias organizadas pela inteligência, mas por dispor temporal e espacialmente os elementos da cena. Os sons, as palavras e os silêncios, inseridos num determinado ritmo, serão o "monograma sensível e sonoro" (MERLEAU-PONTY, 1996b, p. 73) do novo mundo de Mirco e do espectador. Poderíamos aqui parafrasear a afirmação da Fenomenologia da percepção sobre a música, dizendo que, doravante, o som "existe por si e é por ele que todo o resto existe" (MERLEAU-PONTY, 2011a, p. 202).

Até aqui, enquanto espectadores, já nos inserimos de três modos na imagem: com o olhar do diretor, exterior aos personagens (sequência 1); com o olhar do protagonista (sequência 2) e com o olhar dos outros personagens (sequência 3). Essa dinâmica continuará ao longo da película, até o momento em que Mirco se torna completamente cego. A partir daí não nos encarnaremos mais no corpo dos personagens.

$\mathrm{Na}$ cena que se à do refeitório, Mirco explora os outros espaços da escola e a espacialidade do seu próprio corpo. Aí, retornamos ao olhar do diretor, numa belíssima sequência de cenas. Inicialmente, a câmera mostra um plano-detalhe e realiza um plongée ${ }^{13}$, enquadramento no qual visualizamos os pés de Mirco, que andam pela primeira vez, e lentamente, no jardim da escola. Escutamos os sons das folhas arrastadas pelo seu

13- Num ângulo plongée ("mergulho", em francês), a câmera situa-se acima do nível do olhar, voltada para baixo. 
caminhar, bem como o canto dos pássaros e as vozes das outras crianças. Em seguida, o olhar se desloca para um pouco mais longe, dando-nos a sensação de reassumir o lugar de um dos personagens, que observa o andar cuidadoso do menino.

\section{Sequência 4 - Mirco reaprendendo a andar}
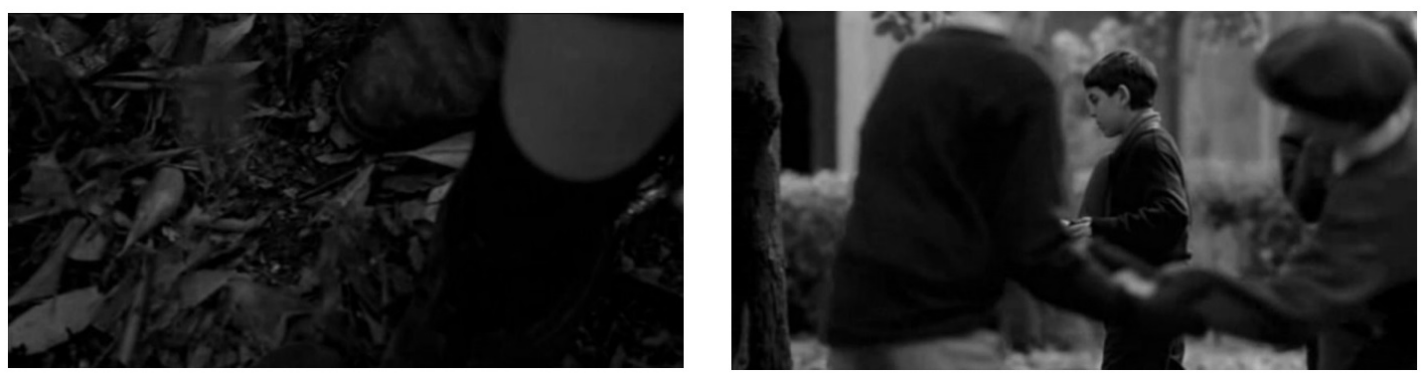

Fonte: DVD de Vermelho como o céu (2006).

Por fim, Mirco encontra Felice ${ }^{14}$, que estava "escondido" em cima de uma árvore. Para juntar-se a ele, Mirco fará novamente o movimento que o cegou: subir. Felice, que é cego de nascença, pede-lhe para explicar as cores, que Mirco via antes do acidente. Para isso, seu novo amigo utiliza um conjunto de sensações: o azul é como andar de bicicleta e sentir o vento bater no seu rosto, ou mesmo como o mar; o marrom é como a casca áspera de uma árvore; o vermelho é como o fogo, ou como o céu no pôr do sol. Ou, ainda, como o sangue que escorreu dos olhos do menino por ocasião do acidente.

Nessa sequência de cenas, retornamos ao olhar do diretor para acompanhar as descrições de Mirco - palavras que se tornam uma verdadeira poesia corporal, reveladoras da estesia e promiscuidade da sensorialidade com o mundo. A sensação causada no espectador é completamente inversa à da cena do acidente - mas não menos intensa.

Aqui, o esquema corporal é convocado pelas metáforas do menino, mostrando que mesmo a participação do espectador no exterior dos personagens - isto é, com o olhar do diretor - mina a nossa compreensão de uma suposta neutralidade da objetividade diante da realidade. Nota-se que, aí, não são os sentidos separadamente que estão em jogo. Ao contrário, é nítido que "eu percebo de uma maneira indivisa com o meu ser total, [...] eu apreendo uma única maneira de existir que fala, ao mesmo tempo, a todos os meus sentidos" (MERLEAU-PONTY, 1996b, p. 63) - o que a cena acima bem manifesta.

Apesar dessa bela introdução às dinâmicas do olhar no filme, fundador de um regime de visibilidade singular, o cineasta mostrará, ao mesmo tempo em que Mirco é punido por brigar com Valério ${ }^{15}$, as atividades que os alunos desenvolviam na escola. Todas elas

14- Felice, também interno do Instituto Cassoni, torna-se o melhor amigo de Mirco e acompanha-o do início ao fim de seu processo de reconfiguração da experiência corporal - da primeira refeição à encenação do fim do ano letivo, passando pelas primeiras experiências de captação dos sons nas dependências do Instituto.

15- Também interno do Instituto Cassoni, mas, diferentemente da maioria, é proveniente de família abastada. Exerce liderança sobre boa parte dos colegas, sendo temido por estes. Primeiramente, percebe em Mirco uma ameaça à sua influência; posteriormente, começa a mudar de comportamento ao envolver-se nas iniciativas daquele. É um personagem usado como exemplo da transformação desencadeada pelo protagonista. 
vinculavam-se à compreensão do corpo "limitado" dos cegos, dando-lhes previamente suas posições precisas no espaço. Tinha-se, aí, uma "espacialidade de posição” (MERLEAUPONTY, 2011a, p. 146).

Os corpos deveriam se habituar a lidar geometricamente com o mundo ao redor, sobretudo com os ofícios a serem aprendidos e tomados como fatum, destino. Por meio de uma aprendizagem baseada na repetição de gestos, os meninos assumiam um trabalho apropriado àquilo que a escola supunha ser o campo de alcance de seu esquema corporal. Em Vermelho como o céu, anatomia era destino e o esquema corporal orientava-se para ele.

Mas, enquanto os meninos aprendiam seus supostos futuros ofícios, Mirco, escutando os mesmos sons das máquinas de tecelagem, descobria outros sons durante o seu castigo. Na sequência, o menino esbarra num armário velho. No início, somos o olhar do diretor; mas, quando da abertura da porta do móvel, assumimos imediatamente o ainda embaçado olhar de Mirco, que vagueia entre o que há ali dentro e tateia os objetos. Tocando um deles em especial, o menino liberou uma narração de uma passagem do Evangelho. Tratava-se de um gravador. A partir dali, Mirco mostrará que o fatum do corpo é outro, completamente diferente daquele que o Instituto Cassoni compreendia.

Medo, angústia, raiva, impotência: esse turbilhão de sentimentos nos invade quando acompanhamos Mirco em sua chegada à nova classe. Logo no início, a câmera nos desloca entre o lugar de um dos personagens da cena, o olhar do diretor e, agora, pela primeira vez, o olhar do professor, Don Giulio. A cena nos revela algo de surpreendente - algo que, se estivéssemos em uma escola de meninos videntes, não nos espantaria tanto.

0 olhar de Don Giulio nos faz ver diversos cartazes nas paredes. Aquela decoração - na qual figuram, inclusive, imagens de alguns com os órgãos do corpo humano - à primeira vista aparece como uma perversa ironia. É ao assumir o olhar do professor que nos damos conta disso. Será também esse olhar que, ao longo da trama, se engajará em um outro modo de conceber a educação daqueles meninos.

Sequência 5 - Do olhar do aluno ao olhar do professor
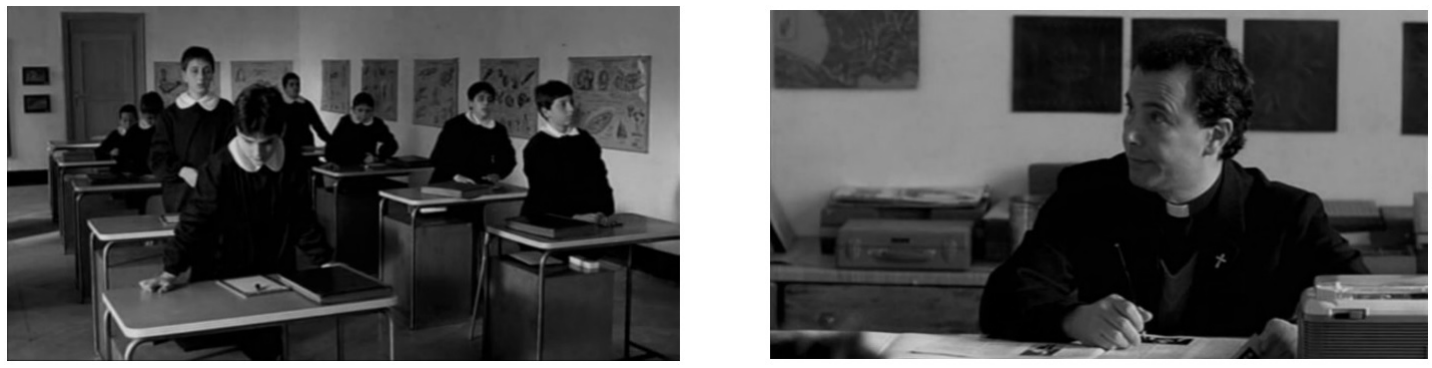

Fonte: DVD de Vermelho como o céu (2006).

Mas retornemos à suposta ironia: ela diz respeito àqueles corpos que não podem ver a representação interior deles mesmos. É como se estivéssemos diante da famosa Lição de Anatomia do Dr. Tulp (1632), de Rembrandt, sendo explicada a quem não pode entendê-la, já que não podem observar e tomar posse intelectual de um objeto do mundo 
- postulado básico da racionalidade moderna. Não podem, como aqueles que assistem à lição, ser iluminados pela luz do conhecimento, da descoberta (NÓBREGA, 2010, p. 45). É como se o conhecimento fosse a eles negado.

No entanto, é justamente com o contrário de uma não aprendizagem que nos deparamos nesta cena. Sabemos que o conhecimento do corpo no Ocidente se deu, na Modernidade, através dos postulados de uma ratio que divide, separa e isola para melhor compreender. Vermelho como o céu, entretanto, revelará meninos que, recusando os esquemas de representação - aos quais a instituição insistia em se vincular - conhecerão o mundo pelo esquema corporal. Nele, não há necessidade de passar pela ideia das coisas (MERLEAUPONTY, 2011a, p. 315). Isto porque o esquema, ao seu modo, é "concreto, visível como um desenho, nós não temos que pensá-lo”, conforme lembrará o filósofo nas notas do curso 0 mundo sensivel e o mundo da expressão (MERLEAU-PONTY, 2011b, p. 133).

$\mathrm{Na}$ sala de Mirco também há outros cartazes - mapas, na verdade -, bem como globos terrestres. E, curiosamente, a primeira aula será de geografia. Considerando que ver não é apropriar-se do que pode ser observado - como o contexto da tela de Rembrandt evoca - e que o corpo - mesmo o dos cegos - "não é cego para si", com Mirco e seus amigos constataremos que o corpo se aproxima do mundo pelo movimento, o que lhes possibilitará rasurar o antigo mapa e criar aquele "mapa do visivel" ao qual Merleau-Ponty se refere em $O$ olho e o espirito, no qual as antigas relações serão refeitas (MERLEAUPONTY, 2004, p. 16).

No desenvolvimento da cena, Mirco tateia sua nova carteira. 0 professor, como de costume, ocupa um bom tempo da aula falando. Nesse caso, porém, há uma diferença: ele não escreve no quadro. Os alunos devem ter os ouvidos bem atentos para transformar os sons em signos de braile. 0 menino, porém, despreza a tabuinha do braile. Diz não precisar dela. Desvia o rosto - como se ainda usasse a visão.

Pacientemente, o professor se aproxima, toma a sua mão e ensina-lhe a como usar o instrumento da escrita para cegos. Ele mostra como o menino deve usar os dedos e o perfurador para escrever, de uma nova forma, os signos da língua. Mas não será fácil fazer Mirco aprender o braile. Na continuidade, insatisfeito e ainda incapaz de aceitar sua nova condição, ele derruba o instrumento. Contudo, o movimento dos dedos e o reconhecimento daquele instrumento ele guardará, pois o utilizará de um outro modo no desenrolar do filme - tal como o datilógrafo ou o instrumentista ao qual alude MerleauPonty na Fenomenologia (MERLEAU-PONTY, 2011a, p. 199-201).

Ora, o que vemos aí, primeiramente, é a possibilidade de se comunicar de outra forma. 0 braile é a invenção de um modo diferente de domínio sobre a língua escrita. Ele, como a multiplicidade de idiomas, mostra-nos a arbitrariedade dos signos à qual MerleauPonty aponta (MERLEAU-PONTY, 2011a, p. 254). Mirco nos revela a rejeição a um modo de comunicar que se enclausura numa única possibilidade - que, no fundo, é, primeiramente, o reconhecimento da não naturalidade da linguagem, da sua contingência. Em segundo lugar, essa não naturalidade se deve à impossibilidade de inserir a corporeidade num processo linear de causa e efeito, de sujeito e objeto, de uma sintaxe cartesiana, dada a dinamicidade e plasticidade do esquema corporal. 
Era assim que a direção de sua escola compreendia a linguagem para os meninos cegos. Um modo de comunicar que, antes, não fazia parte de seu modo de existir. Para que Mirco incorpore o braile, será necessário criar uma outra forma de ver a linguagem - que será, ao invés, de se mover, de sentir e de ouvir, isto é, de outras explorações do esquema corporal. 0 seu professor, na verdade, não desconhecia essas outras possibilidades. Sabia que existiam, por meio dos sentidos, outros modos de "ver" o mundo. E é através de seu apoio que Mirco desenvolverá sua outra linguagem, que atingirá seu ápice, na trama, após a cegueira total do menino.

Nesse momento, o diretor já nos iniciou num outro modo de ver, nascido das imagens criadas pelas explorações sensoriais de Mirco e de seus amigos. A partir de então, enquanto espectadores, não vemos mais com o corpo dos personagens. 0 visível, aí, deixou de ser captação objetiva da realidade, e o movimento, por sua vez, também não é mais uma mudança meramente espacial. Cegos, como Mirco, podemos nos aproximar do visível "não segundo o pensar da proximidade, mas como englobante, investimento lateral, carne", conforme nos lembra Merleau-Ponty nas notas de trabalho de 0 visivel e o invisível (MERLEAU-PONTY, 2012, p. 201, grifo do autor).

Não curiosamente, é a partir da cegueira total do personagem que começamos a partilhar suas emoções de um modo mais intenso. Cada nova descoberta dos sons, dos toques, dos tempos, dos ritmos, da textura das coisas do mundo, ressoa também em nós, no nosso corpo. Experimentamos "certa relação entre o visível e o invisível, onde o invisível não é apenas não-visível (o que foi ou será visto e não o é, ou aquilo que é visto por outro diferente de mim, não por mim)” (MERLEAU-PONTY, 2012, p. 209). Não se trata de uma substituição de um visível objetivo por "um não-visível (que seria apenas ausência objetiva) isto é, presença objetiva alhures” (MERLEAU-PONTY, 2012, p. 224, grifo do autor).

0 que experimentamos com Mirco é "o mundo percebido" enquanto "caminhos de meu corpo", um pertencimento a "um raio de mundo" (MERLEAU-PONTY, 2012, p. 224). Ao mencionar essa concepção de mundo percebido, o filósofo identifica-a à pintura [moderna]. A experiência que fazemos com o personagem é aquela que fazemos com o pintor, quando ele nos dá acesso ao sentido da obra (MERLEAU-PONTY, 2004, p. 83). Logo, é a experiência de um regime expressivo que está em jogo. Esse "mundo irrecusável", a que Mirco chega pela intersensorialidade do corpo em operação, não será mais expresso "em termos de quem enxerga", como faz o pintor, mas em termos de quem encontrou outro modo de experimentar e de formular o visível (MERLEAU-PONTY, 2004, p. 89).

Ora, para Merleau-Ponty, desde a Fenomenologia da percepção, é graças à significação inerente à palavra que a expressão é possivel, pois "a fala ou as palavras trazem uma primeira camada de significação que lhes é aderente e que oferece o pensamento enquanto estilo, (...) antes que como enunciado conceitual" (MERLEAU-PONTY, 2011a, p. 248). Anos depois, ele dirá, em A linguagem indireta e as vozes do silêncio, que este estilo "é em cada pintor o sistema de equivalências que ele se constitui para essa obra de manifestação" (MERLEAU-PONTY, 2004, p. 85).

Como já sublinhamos anteriormente, quando o filósofo se refere ao sistema de equivalências, é a capacidade do esquema corporal de estruturar o mundo percebido 
que está em questão. 0 estilo, presente desde a Fenomenologia ao lado das noções de generalidade e típicos do corpo, acompanha a tentativa do filósofo, até $O$ visível e $o$ invisivel, de expressar a lógica analógica do esquema corporal, que atua a partir de sistemas de equivalências intersensoriais e sensório-motores (SAINT AUBERT, 2014).

Em Mirco, o cinema nos dá a ver essa propriedade de sistema de equivalências, própria do esquema corporal. A experiência vivenciada com este personagem é intensa porque nos insere numa "proximidade vertiginosa" com as coisas, uma "mistura" capaz de gerar uma "relação expressiva”, lembrar-nos-á o filósofo em $O$ mundo sensível e $o$ mundo da expressão (MERLEAU-PONTY, 2011b, p. 56). 0 estilo do pintor "extrai o sistema de equivalências do espetáculo do mundo"; é uma concentração do sentido antes esparso, e que passa a impregnar o quadro (MERLEAU-PONTY, 2004, p. 85).

O sentido perceptivo aparece, portanto, não como "um enunciado, um eu sei que" (MERLEAU-PONTY, 2011b, p. 57, grifo nosso). Com Mirco, experimentamos a perda de um órgão biológico, mas não a possibilidade de expressão. E isso mesmo se ele se recusa a aprender o braile - uma nova tentativa de envelopar os sentidos presentes ao seu redor em torno de uma fórmula enunciativa. A normatividade discursiva dá lugar a outro modo de elaborar o real, que se efetiva no corpo enquanto operador visual. Esse qualificativo do corpo, porém, ultrapassa o enredo, dilatando-se para o conjunto de técnicas utilizadas pelo cineasta para manifestar as suas intenções. Aí, o corpo engajarse-á no ato e criará uma dinâmica interna em nós, borrando a divisão entre interior (cinema) e exterior (espectador) (ANDRIEU, 2014) - experiência que se repetirá em todo o corpus de filmes.

Em Merleau-Ponty, não sendo invólucro do pensamento ou seu acompanhante exterior, a palavra habita as coisas do mundo e, assim, veicula as significações. Afirmando que as palavras não são um simples signo destas coisas, o filósofo abre novos horizontes para a existência da linguagem: ela não é fruto do pensamento. Há, ao contrário, um pensamento na fala. Isso significa que pensar, para o sujeito falante, não é representar o mundo exterior no nosso interior. É aí que linguagem e esquema corporal se unem: do mesmo modo como não precisamos representar o espaço exterior e o nosso corpo para movermo-nos, também não precisamos representar a palavra para chegar ao seu sentido e pronunciá-la.

Nesse sentido, a linguagem faz parte do universo dos usos possíveis do corpo. Ela faz parte do corpo, e dela fazemos uso da mesma maneira que utilizamos nossas mãos ou pés para realizar um movimento. É no contexto de significação gestual, por conseguinte, que se pode compreender a palavra. A palavra é gesto, é atitude corporal. Ela é um lugar no nosso mundo linguístico - e é isso que o corpo de Mirco nos mostra; é isso que sentimos nas múltiplas encarnações que, enquanto espectadores, vivenciamos a partir do filme. Compreendida a partir dessa dimensão espacial, a linguagem tem uma fisionomia. Ela não é um modo de nomear os objetos do mundo ou o pensamento, mas a presença do pensamento no mundo sensível através do corpo, o que Merleau-Ponty havia demonstrado desde a Fenomenologia (MERLEAU-PONTY, 2011a). Trata-se, assim, de uma performance visual. 


\section{Uma performance visual, uma educação do olhar}

A partir de agora, evidenciaremos alguns elementos oriundos das interfaces entre o espectador, o diretor e as imagens. Nessas interfaces se efetua a nossa performance enquanto espectadores que se defrontam com a seleção e montagem feita pelos diretores mas também por nós, quando selecionamos as cenas a serem vistas. Os referidos elementos são: o tipo de corpo com o qual nos defrontamos; o olhar dos personagens; o olhar e o lugar do espectador em relação ao diretor, aos personagens e ao espaço. Trata-se, em suma, da assunção e efetivação de uma performance visual por parte do espectador.

Ao revelar-nos um saber da imagem - isto é, um saber oriundo de uma determinada partilha do visível -, essa performance nos posiciona no núcleo da experiência do moderno. Nela se deteve Merleau-Ponty em $O$ olho e o espirito, ao pôr-se em busca da ciência secreta - muito embora habitante do visível e, por isso, paradoxalmente, às claras - que animava o pintor. Esta outra configuração do saber aqui esboçada nos confere os instrumentos para, transformando-nos em pesquisadores-diretores, realizarmos uma montagem do visível para a educação.

Fazemo-lo a fim de desenvolvermos as implicações de tais interfaces no que concerne ao cinema como educação do olhar. Alargamos, assim, com a noção de montagem no cinema, aquilo que a incursão merleau-pontiana na noção de carne, em seus últimos escritos, manifesta. Pela imagem, nossa interrogação instala-se no contexto de uma certa inquietude sensivel. Inquietude que, nascida do exercício do olhar, transborda-o, perturbando o saber que construímos sobre a inteligibilidade do real. Ao centrar o nosso exercício no universo da visibilidade, notamos a capacidade do cinema de revelar dimensões da corporeidade que, não raro, passam despercebidas. É a invisibilidade do visível que está em questão - não porque há algo supostamente escondido, como numa espécie de ideologia subterrânea do ou no corpo. É certo que as câmeras mostram, não raro, as intenções do cineasta; contudo, nem mesmo tais intenções podem controlar a contingência dos efeitos das imagens no espectador. Os cineastas controlam ângulos, tomadas e mesmo a montagem, mas nada disso impede efeitos inesperados a partir das cenas. As câmeras liberam, involuntariamente, a multidão de monstros que saíam do livro aberto pelo Santo Antônio de Flaubert ${ }^{16}$. A montagem do visível é iniciada pelo diretor e continuada pelo espectador, que terá de lidar com as exigências das imagens.

Salientamos a própria modalidade da experiência suscitada pelas imagens do cinema, a qual diz respeito e envolve, ao mesmo tempo, o espectador e os personagens. Nela, de um lado, percebemos os efeitos que as imagens causam em nós ao interrogar o nosso olhar e fazer-nos ver diferentemente o visível - posto que nos imergem nele (MERLEAU-PONTY, 2004) - efeitos estes provenientes justamente do processo de imagem. De outro lado, esse processo é da mesma natureza daquele vivenciado por Mirco (e pelos outros personagens) em seu engajamento numa ordem sensível. A friç̧ão que a ficção das

16- Referência à obra A tentação de Santo Antônio, de Gustave Flaubert. 
imagens causa em nós, espectadores, encontra sua correspondência na ficção da fricção do processo vivido pelos personagens.

Em Vermelho como o céu, Mirco, devido à cegueira, é impossibilitado de ler e deve aprender uma "nova língua", o braile. 0 menino, na verdade, pela experiência corporal, desenvolverá um modo completamente original de expressão, "reaprendendo a ver o mundo". Nós também, enquanto espectadores, experimentamos o cinema como educação do olhar. Assistimos aos filmes - mas não do exterior, tal como o espectador da Dióptrica. Não nos situamos em relação à imagem como quem tem um poder divino ou ciclópico em face do real, mas engajamo-nos numa performance que nos leva, na verdade, a "assistir por dentro a fissão do ser" (MERLEAU-PONTY, 2004, p. 42). Nela, há "inerência daquele que vê ao que ele vê" (MERLEAU-PONTY, 2004, p. 17). 0 cinema, em todas as suas etapas - enredo, montagem, decupagem, exibição - desencadeia uma potencialidade educativa tanto a partir do campo de análise que ele descortina ao rasgar o real pela ficção, tanto quando pela mediação visual da gestualidade corporal.

A experiência fílmica, como a pintura, rejeita um pensamento operacional com o espaço. Nela temos um pensamento de contato, já que a visão do cineasta, como a do pintor, se faz gesto, e um gesto que, por seu turno, é pensamento. Aqui, tal qual Santo Antônio, nós assumimos o lugar daquilo que vemos, dada a nossa inerência ao visível, por sermos feito do mesmo estofo dele (MERLEAU-PONTY, 2004). Nele, age o nosso "corpo operante e atual, aquele que não é uma porção do espaço, um feixe de funções" mas "um trançado de visão e de movimento" (MERLEAU-PONTY, 2004, p. 16). Instalamo-nos num espaço outro, que nos doa, por conseguinte, outros horizontes.

Ora, essa educação do olhar na qual imergimos e na qual Mirco, engajado num processo da ordem da imagem, igualmente está, é possível graças à reversibilidade carnal, característica da experiência do corpo operante no mundo. Tal reversibilidade contrapõe-se, evidentemente, a uma reversibilidade lógica com o espaço. 0 cinema nos mostra muito mais que o movimento-deslocamento. Em 0 mundo sensível e o mundo da expressão, ele desenvolverá tal caráter afirmando que o cinema cria a expressão, mas é "interiormente animado por ela”, e "o deslocamento local não é visto senão através de uma rede de signos cujo sentido é ultra-espacial”. Esse sentido é oriundo do "problema de organização que eles põem ao nosso ser psico-físico” (MERLEAU-PONTY, 2011b, p. 169) enquanto espectadores. Trata-se, ao invés, do amálgama da visão e do movimento, tal qual evocará, anos depois, $O$ olho e o espirito.

Assim, se o cinema educa - ou se nos inserimos numa educação de si pelo olhar, no cinema - é porque nos engajamos nessa fissão do Ser que o corpo vidente-visível, em sua reversibilidade, nos permite. Uma fissão que abre vias para uma outra ontologia, posto que dessa experiência motora-visual, novos modos de ser e de pensar são liberados. Essa educação implica ainda a realidade de uma relação imprevisível com um tempo irreversível e um sentido inesgotável - o que dispensa um sujeito cuja intenção seja sugar todo o sentido do real.

Trata-se, na verdade, de um "renunciar ao visto da intencionalidade, à coisa identificada, apreendida ou consumida, por um visivel fora do tempo”, como lembra Imbert (2010, p. 285, grifo da autora). Imbert refere-se, aqui, às novas geometrias do visível sobre as quais se 
deteve Baudelaire. Ver, agora, ultrapassa os protocolos que marcaram a filosofia moderna e também a linguagem fenomenológica - mormente no que concerne à intencionalidade da consciência - e se liga a uma redefinição do nosso protocolo de relação com o real. MerleauPonty esboçou essa nova geometria do visível por meio da carne.

A carne, figura máxima do inacabamento próprio da atividade expressiva, não reclama nenhuma positividade diante do real. Ela não entoa uma ladainha do "lamento de não ser tudo" (MERLEAU-PONTY, 2004, p. 46). 0 filósofo encontra, por meio da "pregnância do visual no som e na palavra" presentes no cinema, uma linguagem indireta que desestabiliza as nossas maneiras de aproximação com o real. Isto porque, mesmo o que compreendemos por "elementos realistas" só são verdadeiros quando inscritos na ordem da imagem, caracterizadas pela "montagem, decupagem, ritmo sonoro-visual etc." (MERLEAU-PONTY, 2011b, p. 169), que desvela a sua contingência - que é contingência da expressão - e o seu inacabamento perpétuo.

\section{Considerações finais}

0 registro do inteligivel é perturbado por esse trabalho de exigência visual desencadeado pela imagem cinematográfica. Se, em $O$ olho e o espírito, o filósofo lança mão da profundidade na pintura moderna para demonstrar como a ordem da representação no espaço pictural foi modificada - desequilibrando o protocolo da percepção, outrora fundado na perspectiva - com o cinema, é a inerência entre o vidente e o visível que o faculta. Assim, a enunciação do real não se restringe mais à ordem binária da identidade e da diferença, ao valor de verdade entre proposições, à adaequatio rei et intellectum ${ }^{17}$ de Tomás de Aquino ou a qualquer outro modo de dizer o real no qual a experiência se restrinja ao universo lógico ou de uma teoria do conhecimento enredada nas teias do kantismo ou das filosofias da consciência.

Isto porque "sustentando a incorporação, a reversibilidade carnal se realiza aquém da objetivação ou plena diferenciação entre sujeito e objeto” (SAINT AUBERT, 2013, p. 269). A educação suscitada pelo cinema caracteriza-se por uma lógica das "lacunas" que "realizam emblemas para significações que eu não possuía” (MERLEAU-PONTY, 2011b, p. 170). A imagem, situando-nos nas lacunas, borra os limites entre o visível e o invisível, o vidente e o visto - como o filósofo evocará pelos conhecidos exemplos da mão que toca e é ao mesmo tocada, em $O$ visivel e o invisível.

0 Ser - esse avatar da ontologia clássica - é fissurado, mas não para implodilo e destruí-lo, como o verbo pode sugerir, e sim para, através da atividade expressiva do corpo, rearticular o visivel segundo significações que lhe transcendem (MERLEAUPONTY, 2011b); para, igualmente, na promiscuidade do corpo com o mundo, oferecer, a partir dele, uma outra prosa do mundo $^{18}$, como o fizeram Baudelaire, Flaubert e outros ícones da modernidade na literatura e nas artes. 0 protocolo da percepção e o registro do inteligivel, acostumados que eram a contar com a clara separação entre um sujeito que

17- Fórmula filosófica segundo a qual há uma correspondência, uma adequação entre a realidade das coisas e 0 intelecto.

18- Referência à obra A prosa do mundo (1969), de Merleau-Ponty. 
conhece e um objeto que é conhecido, são atordoados. 0 cinema, destarte compreendido como educação do olhar, faculta-nos modos outros de dizer, de ver, de pensar e de ser na e para a realidade educativa. É, portanto, um “reaprender a ver o mundo" - injunção realizada pelo filósofo já na Fenomenologia da percepção - que está em questão, o que passa, sem dúvida, pela necessidade de uma epistemologia que dê conta das exigências das imagens.

\section{Referências}

ALLOA, Emmanuel. Entre a transparência e a opacidade - 0 que a imagem dá a pensar. In: ALLOA, Emmanuel (Org.). Pensar a imagem. Belo Horizonte: Autêntica, 2015. p. 7-1a

ANDRIEU, Bernard. Donner le vertige: les arts immersifs. Montréal: Liber, 2014.

BARBARAS, Renaud. De l'être du phénomène: sur l'ontologie de Merleau-Ponty. Grenoble: Jérome Millon, 2001.

BARBARAS, Renaud. Le tournant de l'expérience: recherches sur la philosophie de Merleau-Ponty. Paris: Vrin, 2013.

BIMBENET, Étienne. Nature et humanité: le problème anthropologique dans l'œuvre de Merleau-Ponty. Paris: Vrin, 2004.

FISCHER, Rosa Maria Bueno. Televisão \& educação: fruir e pensar a TV. 4. ed. Belo Horizonte: Autêntica, 2013.

FOUCAULT, Michel. Des espaces autres. In: FOUCAULT, Michel. Dits et écrits II. Paris: Gallimard, 2001. p. 1571-1581

FOUCAULT, Michel. Les hétérotopies. In: FOUCAULT, Michel. Le corps utopique suivi de les hétérotopies. Paris: Lignes, 2009. p. 23-36.

FRESQUET, Adriana Mabel. Cinema e educação: reflexões e experiências com professores e estudantes dentro e fora da escola. 1. ed. Belo Horizonte: Autêntica, 2013.

DUARTE, Rosália Maria. Cinema e educação. 2. ed. Belo Horizonte: Autêntica, 2006.

IMBERT, Claude. Pour une histoire de la logique: un héritage platonicien. Paris: Presses Universitaires de France, 1999.

IMBERT, Claude. Os contornos indeterminados do moderno. In: NOVAES, Adauto (Org.). Mutações: a experiência do pensamento. São Paulo: SESC SP, 2010. p. 91-106

IMBERT, Claude. Merleau-Ponty sob a injunção do moderno. In: CAMINHA, Iraquitan de Oliveira; NÓBREGA, Terezinha Petrucia (Org.). Compêndio Merleau-Ponty. São Paulo: LiberArs, 2016. p. 13-25. 
LEFORT, Claude. Qu'est-ce que voir? In: LEFORT, Claude. Sur une colonne absente: écrits autour de Merleau-Ponty. Paris: Gallimard, 1978. p. 140-155

LIMA NETO, Avelino Aldo. NÓBREGA, Terezinha Petrucia. Corpo, cinema e educação: cartografias do ver. Holos, Natal, v. 5, p. 81-97, 2015.

MERLEAU-PONTY, Maurice. Fenomenologia da percepção. São Paulo: Martins Fontes, 2011a.

MERLEAU-PONTY, Maurice. La guerre a eu lieu. In: MERLEAU-PONTY, Maurice. Sens et non-sens. Paris: Gallimard, 1996a. p. 169-170.

MERLEAU-PONTY, Maurice. Le cinéma et la nouvelle psychologie. In: MERLEAU-PONTY, Maurice. Sens et non-sens. Paris: Gallimard, 1996b. p. 61-75.

MERLEAU-PONTY, Maurice. Le monde sensible et le monde de l'expression. Genève: MetisPresses, $2011 \mathrm{~b}$. Notes de cours au Collège de France, 1953.

MERLEAU-PONTY, Maurice. L'ontologie cartésienne et l'ontologie aujourd'hui. In: MERLEAU-PONTY, Maurice. Notes de cours 1959-1961. Paris: Gallimard, 1996c. p. 159-268.

MERLEAU-PONTY, Maurice. 0 olho e o espírito. In: MERLEAU-PONTY, Maurice. 0 olho e o espírito seguido de A linguagem indireta e as vozes do silêncio e A dúvida de Cézanne. São Paulo: Cosac \& Naify, 2004. p. 13-46.

MERLEAU-PONTY, Maurice. 0 visível e o Invisível. São Paulo: Perspectiva, 2012.

NÓBREGA, Terezinha Petrucia. Sentir a dança ou quando o corpo se põe a dançar... Natal: UFRN, 2015.

NÓBREGA, Terezinha Petrucia. Uma fenomenologia do corpo. São Paulo: Livraria da Física, 2010.

NOITE e neblina. Direção Alain Resnais. 1955. DVD (32 min), preto e branco. Título original: Nuit et brouillard. PLATÃO. Teeteto. Lisboa: Fundação Calouste Gulbenkian, 2010.

PLATON. Oeuvres complètes. Tome VIII. 2. partie. Théétète. Paris : Belles Lettres, 1923.

PLATON. Oeuvres complètes. Tome VIII. 3. partie. Le Sophiste. Paris : Belles Lettres, 1955.

REVEL, Judith. Foucault avec Merleau-Ponty: ontologie politique, présentisme et histoire. Paris: Vrin, 2015.

SAINT AUBERT, Emmanuel. Être et chair: du corps au désir: I'habilitation ontologique de la chair. Paris: Vrin, 2013.

VERMELHO como o céu. Direção Cristiano Bortone. Oriza Produzioni, 2006. DVD (96 min), color. Título original: Rosso come il cielo. 
VEYNE, Paul. Le pain et le cirque: sociologie historique d'un pluralisme politique. Paris: Éditions du Seuil, 1976.

Recebido em: 05.04.2016

Aprovado em: 02.02.2017

Avelino Aldo de Lima Neto é doutor em educação pela Universidade Federal do Rio Grande do Norte (UFRN) e pela Université Paul Valéry - Montpellier III. Professor do Instituto Federal de Educação, Ciência e Tecnologia do Rio Grande do Norte. Docente do Programa de PósGraduação em Educação da UFRN. Pesquisador do Grupo de Pesquisa Estesia - Corpo, Fenomenologia e Movimento.

Terezinha Petrucia da Nóbrega é doutora em educação pela Universidade Metodista de Piracicaba. Professora Titular do Departamento de Educação Física da Universidade Federal do Rio Grande do Norte (UFRN). Docente dos programas de Pós-Graduação em Educação e em Educação Física da UFRN. Coordenadora do Grupo de Pesquisa Estesia - Corpo, Fenomenologia e Movimento. 